\title{
perguruan silat Bandrong RENGgong AMPEL \\ DI KABUPATEN SERANG
}

\author{
SILAT INSTITUTION OF BANDRONG RENGGONG AMPEL \\ IN THE REGENCY OF SERANG
}

\author{
Oleh EuisThresnawaty S \\ Balai Pelestarian Sejarah dan Nilai Tradisional Bandung \\ Jl. Cinambo No. 136 Ujungberung Bandung \\ Email: euisthresnawaty@yahoo.com
}

Naskah Disetujui: 8 Februari 2013

\begin{abstract}
Abstrak
Pencak silat merupakan seni bela diri yang berakar dari budaya asli bangsa Indonesia. Perkembangan dan penyebaran silat secara historis mulai tercatat ketika penyebarannya banyak dipengaruhi oleh kaum ulama, seiring dengan penyebaran agama Islam pada abad ke-15 di Nusantara. Demikian pula halnya pencak silat Banten Bandrong, mulai dikenal seiring dengan berdirinya kerajaan Islam Banten. Saat ini silat asli Banten mulai kurang diperhatikan keberadaannya. Salah satu sebab ditinggalkannya seni dan budaya pencak silat asli Banten ini karena manajemen perguruan silat yang masih bersifat seadanya, padahal transformasi pengelolaan dari metode tradisional ke arah yang lebih modern mutlak diperlukan seiring dengan perkembangan zaman. Atas dasar itu, maka dilakukan penelitian mengenai Perguruan Silat Bandrong Renggong Ampel di Kabupaten Serang dengan tujuan mengungkapkan latar belakang perjalanan sejarah serta dinamika perkembangannya. Adapun metode yang digunakan adalah metode sejarah dengan melakukan wawancara. Pada kenyataannya dengan pengelolaan yang terorganisasi silat bandrong yang merupakan seni asli Banten ini dapat lebih dikenal oleh masyarakat luas.
\end{abstract}

Kata kunci: bandrong, silat, silat asli Banten.

\begin{abstract}
Pencak silat is a kind of martial art that has root in original culture of Indonesia. Its development and spreading were historically recorded when the ulamas (Islamic scholars) influence it along with the spreading of Islam in the Archipelago during $15^{\text {th }}$ century. Pencak silat Bandrong became familiar along with the establishment of the Islamic Kingdom of Banten. Today it is gradually abandoned due to mismanagement in the organization, whereas it is necessary to transform traditional management into modern one. Based on this fact the author conducted this research in order to reveal the background of its historical course and dynamics of its development. History method and
\end{abstract}


interview were used in the research. In fact, good management could make Bandrong martial art more familiar to society.

Keywords: bandrong, original martial art of Banten.

\section{A. PENDAHULUAN}

Pencak silat adalah sistem yang terdiri atas sikap (posisi) dan gerak-gerik (pergerakan). Ketika seorang pesilat bergerak sewaktu bertarung, sikap dan gerakannya berubah mengikuti perubahan posisi lawan secara berkelanjutan. Setelah menemukan kelemahan pertahanan lawan, pesilat akan mencoba mengalahkan lawan dengan suatu serangan yang cepat (Dahlan, 2011: 262 ).

Pencak silat merupakan seni bela diri yang berakar dari budaya asli bangsa Indonesia. Disinyalir dari abad ke-7 Masehi silat sudah menyebar ke pelosok Nusantara. Kala itu pencak silat telah diajarkan bersama-sama dengan pelajaran agama di pesantren-pesatren dan surausurau. Budaya salat dan silat menjadi satu keterikatan erat dalam penyebaran pencak silat. Silat lalu berkembang dari sekadar ilmu bela diri dan seni tari rakyat, menjadi bagian dari pendidikan bela negara untuk menghadapi penjajah. Di samping itu juga pencak silat menjadi bagian dari latihan spiritual.

Banten yang namanya sangat dikenal untuk ilmu silatnya, juga penyebarannya tidak terlepas dari ajaran agama Islam. Banyak nama dari jurus dan gerakan perguruan silat asli Banten diambil dari aksara dan bahasa arab. Pencak silat Banten mulai dikenal seiring dengan berdirinya kerajaan Islam Banten yang didirikan pada abad 15 Masehi dengan raja pertamanya Sultan Hasanudin. Perkembangan pencak silat pada saat itu tidak terlepas dari dijadikannya silat sebagai alat untuk penggemblengan para prajurit kerajaan sebagai bekal ketangkasan bela negara yang diajarkan oleh para guru silat yang menguasai berbagai aliran. Silat juga sebagai dasar alat pertahanan kerajaan dan masyarakat umum Banten dalam memerangi para penjajah.

Bandrong sebagai warisan seni dan budaya pencak silat asli Banten tertua selayaknya mendapat perhatian lebih dari para pewaris aliran ini. Transformasi pengelolaan dari metode tradisional ke arah yang lebih modern mutlak diperlukan seiring dengan perkembangan zaman. Kesadaran akan perlunya manajemen yang baik diaplikasikan oleh para murid dan sesepuh bandrong di Desa Ampel dengan membentuk kepengurusan formal dengan nama Padepokan Bandrong Renggong Ampel.

Penelitian ini mempunyai tujuan untuk mendapatkan gambaran tentang sejarah silat bandrong, khususnya Perguruan Silat Bandrong Renggong Ampel di Kabupaten Serang dan mengetahui perkembangannya. Metode yang digunakan adalah metode sejarah dengan melalui empat tahapan, yaitu: heuristik atau proses pencarian dan pengumpulan sumber. Pada tahap heuristik ini digunakan teknik-teknik sebagai berikut: studi kepustakaan, penelitian di lapangan, dan melakukan wawancara dengan tokoh-tokoh yang berperan atau mengetahui mengenai Perguruan Silat Bandrong Renggong Ampel Kabupaten Serang. Kemudian dilakukan kritik sumber, baik kritik ekstern (tentang wujud sumber) atau kritik intern (tentang isi sumber) serta melakukan perbandingan data yang berasal dari macam-macam sumber. Dilanjutkan dengan tahap interpretasi, yaitu proses pemberian makna dan penafsiran secara jelas dan lengkap, dan akhirnya tahapan historiografi yaitu proses terakhir dalam penulisan sejarah yang berupa proses merangkaikan faktafakta yang berhasil dihimpun dalam sebuah kisah sejarah. 


\section{B. HASIL DAN BAHASAN}

\section{Gambaran Umum Wilayah}

Kabupaten Serang yang terletak di ujung Pulau Jawa bagian barat adalah salah satu kabupaten dari 3 kabupaten dan 4 kota di wilayah Provinsi Banten yaitu Kabupaten Lebak, Kabupaten Pandeglang, Kabupaten Tangerang, Kota Cilegon, Kota Tangerang, Kota Tangerang Selatan, dan Kota Serang. Luas wilayah Kabupaten Serang adalah $1.734,09 \mathrm{~km}^{2}$. Terletak pada posisi koordinat antara $105^{\circ} 7^{\prime}-105^{\circ} 22^{\prime}$ Bujur Timur dan $5^{\circ} 50^{\prime}-6^{\circ} 21^{\prime}$ Lintang Selatan. Secara administratif Kabupaten Serang terbagi atas 28 wilayah kecamatan dan 308 desa. Kecamatan yang ada di wilayah Kabupaten Serang adalah: Kecamatan Pulo Ampel, Bojonegara, Kramatwatu, Padarincang, Mancak, Anyer, Cinangka, Waringin Kurung, Pabuaran, Gunung Sari, Baros, Ciomas, Petir, Tunjung Teja, Cikeusal, Pamarayan, Bandung, Jawilan, Kopo, Cikande, Kibin, Binuang, Kragilan, Carenang, Ciruas, Tirtayasa, Tanara, dan Pontang. Rencananya pusat pemerintahan berada di Kecamatan Ciruas. Pada tanggal 17 Juli 2007 Kabupaten Serang dimekarkan menjadi Kota Serang dan Kabupaten Serang.

Secara geografis, sebelah utara Kabupaten Serang berbatasan dengan Laut Jawa dan Kota Serang, di sebelah timur berbatasan dengan Kabupaten Tangerang, di sebelah selatan dengan Kabupaten Lebak dan Kabupaten Pandeglang, sedangkan di sebelah barat berbatasan dengan Kota Cilegon dan Selat Sunda. Kabupaten Serang merupakan pintu gerbang atau transit perhubungan darat antarpulau Jawa dan Pulau Sumatera, Kabupaten Serang pun sangat strategis karena dilalui oleh jalan tol MerakJakarta, juga sebagai daerah alternatif dan penyangga (hinterland) ibu kota negara, karena dari Kota Jakarta hanya berjarak sekitar 70 kilometer.

Letak Kabupaten Serang yang sangat strategis membuat akses ke mana saja menjadi mudah. Lancarnya arus lalu lintas akan menunjang pembangunan dan perkembangan perekonomian suatu daerah. Bandara Internasional Soekarno-Hatta yang terletak di wilayah Kabupaten Tangerang memiliki jarak sangat dekat dengan Kabupaten Serang. Kabupaten Serang rencananya akan memiliki pelabuhan laut modern yang akan dibangun di Kecamatan Bojonegara seluas 455 hektar, sehingga akan dapat menunjang kegiatan perekonomian dengan akselerasi lebih cepat. Sekarang ini perhubungan antarpulau untuk penumpang dilakukan melalui Pelabuhan Merak di Kota Cilegon, untuk perdagangan dan barang-barang dilakukan di Pelabuhan Cigading dan Pelabuhan Karangantu, yaitu pelabuhan tua bersejarah yang pernah menjadi pelabuhan terbesar di kawasan Asia di masa lampau.

Iklim di wilayah Kabupaten Serang termasuk tropis dengan musim hujan antara November - April dan musim kemarau antara Mei - Oktober. Curah hujan rata-rata $3,92 \mathrm{~mm} /$ hari. Temperatur udara rata-rata berkisar antara $25,8^{\circ}$ Celsius $-27,6^{\circ}$ Celsius. Temperatur udara minimum $20,90^{\circ}$ Celsius dan maksimum $33,8^{\circ}$ Celsius. Tekanan udara dan kelembaban nisbi rata-rata $81,00 \mathrm{mb} / \mathrm{bulan}$. Kecepatan arah angin rata-rata 2,80 knot, dengan arah terbanyak adalah dari barat.

Jumlah penduduk Kabupaten Serang pada tahun 2008 adalah 1.826 .146 orang terdiri dari 948.753 laki-laki dan 877.393 perempuan. Pada tahun 2009 jumlah total penduduk Kabupaten Serang turun menjadi 1.345.557 orang terdiri 684.155 laki-laki, dan 661.402 perempuan. Menurut data tahun 2010 jumlah penduduk Kabupaten Serang mengalami kenaikan kembali menjadi 1.571.174 jiwa, dengan komposisi laki-laki dan perempuan berimbang, dan laju populasi $2 \%$.

Tingkat pendidikan masyarakat Kabupaten Serang relatif baik. Kabupaten Serang memiliki 94 sekolah dasar (SD), 92 buah sekolah lanjutan tingkat pertama (SLTP), 35 buah sekolah menengah 
umum, 4 buah sekolah menengah kejuruan (SMK), 5 buah akademi, dan 7 buah perguruan tinggi (PT).

Latar belakang budaya yang kental dan sejarah heroik rakyatnya melawan penjajah Belanda dulu memberikan warisan warna khas keteguhan dan kegigihan masyarakat Serang dalam membangun wilayah Serang untuk kesejahteraan dan kemakmuran bersama secara maksimal. Semuanya tercermin pada lambang Kabupaten Serang yang bermotokan "Sepi Ing Pamrih, Rame Ing Gawe " yang berarti " Semangat untuk Selalu Bekerja Keras, Tanpa Mengharap Imbalan " .

\section{Sejarah Silat Bandrong}

Mendapatkan sumber tertulis yang berkaitan dengan sejarah silat bandrong ini ternyata cukup sulit, bahkan bisa dikatakan tidak ada, kalaupun ada cenderung hanya tulisan sederhana berbentuk cerita. Sementara itu untuk wawancara dengan tokoh sezaman pun tidak mungkin. Untuk itulah selain digunakan sumber tertulis yang ada secara khusus digunakan sumber lisan berdasarkan wawancara dengan tokoh-tokoh bandrong yang dianggap memahami latar belakang silat bandrong.

Silat bandrong lahir sekitar tahun 1500 Masehi, yaitu sebelum berdirinya Kesultanan Banten. Tokoh yang diketahui pertama menyebarkan aliran ini adalah seorang kiai bernama Ki Agus Jo, dikenal dengan nama Ki Beji. Ia terkenal sebagai kiai sekaligus pendekar dan merupakan guru besar bandrong yang menetap di salah satu lereng Gunung Santri. Di antara para muridnya yang terkenal adalah $\mathrm{Ki}$ Sarap dan Ki Ragil yang berasal dari Kampung Gudang Batu, Waringin Kurung (Wawancara dengan Ali Rahim dan Ahmad Faroji Jauhari, 9-10 April 2012).

Pada saat salah satu senopati Kesultanan Banten meninggal, Sultan Hasanuddin kemudian mengangkat murid Ki Beji yang bernama Ki Sarap untuk menjadi senopati di Kesultanan Banten dengan gelar Senopati Nurbaya. Selanjutnya Senopati Nurbaya atau lebih dikenal dengan sebutan Ki Nurbaya ditugaskan oleh Sultan Hasanudin untuk mengamankan wilayah Laut Jawa, terutama Teluk Banten dan Pelabuhan Karangantu dengan markas di Bojonegara. Pada masa itu banyak pedagang asing masuk ke wilayah Banten, juga masih banyak perompak atau bajak laut.

Pengangkatan Ki Sarap menjadi senopati bermula dari suatu peristiwa, yaitu ketika Sultan Maulana Hasanudin dinobatkan menjadi sultan di Banten (1552-1570), ia mempunyai seorang senopati atau patih yang bernama Kiai Semar (Ki Semar) yang berasal dari Kampung Kemuning Desa Tegal Luhur. Seperti biasanya setiap hari Jumat ia selalu meminta izin kepada sultan untuk kembali ke kampungnya karena pada hari tersebut ia harus berdagang daging kerbau di Pasar Balagendong Desa Binuangeun (dulu kecamatan).

Pada suatu hari ketika Ki Semar sedang berjualan di lapaknya, tiba-tiba datang seseorang yang akan membeli dagangannya. Orang itu bernama Kiai Asyraf (Ki Sarap) dengan tujuan membeli limpa atau sangket. Tetapi akibat Ki Semar yang telah menyepelekan Ki Sarap karena dianggap orang miskin yang tidak mampu membeli limpa akhirnya terjadi bentrok fisik. Tangan Ki Sarap dikelit dan ditekuk ke belakang punggung oleh Ki Semar, tapi meskipun diperlakukan demikian Ki Sarap diam saja menahan amarah karena kejadian tersebut berlangsung di tempat umum.

Menjelang siang, Ki Semar mulai beranjak pulang menuju rumahnya di Kampung Kemuning. Ia berjalan tergesagesa karena pada hari itu ia harus mengejar salat Jumat berjamaah. Di tempat yang sepi antara Balagendong dan Kampung Kemuning, tiba-tiba muncul Ki Sarap menghadang $\mathrm{Ki}$ Semar dan langsung menyerangnya. Keduanya masing-masing mengeluarkan ilmu ketangkasan dan kehebatannya. Mereka berdua memang 
sama-sama kuat, tangkas dan sakti. Perkelahian mereka berlangsung hingga menjelang magrib.

Perkelahian yang sangat alot itu diakhiri dengan ditebasnya kepala $\mathrm{Ki}$ Semar oleh golok $\mathrm{Ki}$ Ragil yang dilemparkan ke arah $\mathrm{Ki}$ Sarap dan langsung ditebaskan ke leher Ki Semar. Dengan sekali tebas kepala Ki Semar pun terpental puluhan meter, lalu berputar seperti gangsing kemudian menghujam ke dalam tanah. Hingga saat ini, tempat kepala terkubur itu berada di pinggir sungai di tepi hutan antara Balagendong dan Kampung Kemuning. Selesai sudah perkelahian itu yang dimenangkan oleh $\mathrm{Ki}$ Sarap. Masyarakat yang menyaksikan adu kekuatan itu segera mengangkat tubuh $\mathrm{Ki}$ Semar yang tanpa kepala dibawa ke kampung untuk diurus sebagaimana mestinya kemudian dimakamkan di Kampung Kemuning Desa Tegal Luhur.

Kabar kematian Ki Semar yang saat itu menjabat sebagai senopati tanah Banten, merupakan berita yang menghebohkan. Berita itu dibicarakan di hampir semua tempat orang berkumpul. Berita itu pun akhirnya sampai kepada Sultan Maulana Hasanudin di Banten. Mendengar berita tersebut sultan sangat terkejut dan marah. Kemudian ia memerintahkan kepada punggawanya untuk menangkap Ki Sarap yang dianggap sebagai pembunuh Ki Semar sang senopati Banten.

Barisan tentara segera diberangkatkan ke Gudang Batu untuk menangkap $\mathrm{Ki}$ Sarap yang kemudian dihadapkan kepada sultan karena akan diadakan pengusutan lebih lanjut tentang pembunuhan itu. Selanjutnya atas perintah Sultan Banten, Ki Sarap dimasukkan ke dalam penjara dan akan dihukum mati di tiang gantungan.

Dalam suatu musyawarah mengenai hukuman yang akan dijatuhkan kepada Ki Sarap, permaisuri sultan mengemukakan pendapatnya bahwa hukuman mati untuk Ki Sarap sangat tidak tepat dengan alasan:
1. Ki Sarap dan $\mathrm{Ki}$ Semar bertarung mengadu kesaktian, dan karena $\mathrm{Ki}$ Sarap membela diri sendiri berarti hal itu bukanlah pembunuhan.

2. Kerajaan Banten sangat membutuhkan orang-orang yang gagah berani, kuat dan banyak ilmunya seperti Ki Sarap untuk menghadapi musuh yang lebih besar lagi. Hal ini jelas Ki Sarap lebih kuat dengan berhasilnya dia mengalahkan Ki Semar yang saat itu menjabat senopati Banten.

Setelah melalui musyawarah bersama para pembantu sultan, akhirnya pendapat permaisuri diterima oleh sultan. Selanjutnya Ki Sarap dipanggil menghadap Sultan Maulana Hasanudin dan dijelaskan oleh sultan bahwa hukuman mati untuknya dibatalkan. Kemudian Ki Sarap diberi tugas untuk menggantikan $\mathrm{Ki}$ Semar sebagai senopati Kesultanan Banten dengan syarat harus mau melalui ujian ketangkasan, yaitu menembak antinganting (gegombel) tudung permaisuri sultan tanpa melukainya sedikit pun.

Persyaratan tersebut diterima oleh $\mathrm{Ki}$ Sarap, walaupun dia tahu risikonya sangat tinggi mengingat ia bukanlah seorang ahli dalam hal menembak. Ki Sarap meminta waktu selama tiga hari sebelum ujian tersebut dilaksanakan. Ia meminta izin pulang ke kampungnya di Gudang Batu. Setelah sampai di kampungnya, Ki Sarap segera menghadap kepada kakaknya yaitu Ki Ragil dan memberitahukan masalah yang sedang dihadapinya. Ki Ragil pun memberinya suatu benda yang harus dimasukkan ke dalam senapan saat pelaksanaan. Kemudian $\mathrm{Ki}$ Ragil memberi beberapa petunjuk tata cara menembakkan senjata. Setelah semua pesan dari $\mathrm{Ki}$ Ragil dipahaminya, Ki Sarap memohon doa dari kakaknya untuk segera kembali menghadap Sultan Maulana Hasanudin di Banten.

Pada hari yang telah ditentukan, tibalah saat yang dinanti-nantikan oleh seluruh masyarakat Banten, karena pada 
hari itu sultan akan menguji ketangkasan seorang calon senopati Banten. Di tengah alun-alun sang permaisuri duduk di kursi yang berada di sebelah timur menghadap ke arah barat, dengan jarak sekitar 30 meter, Ki Sarap berdiri berhadapan dengan permaisuri. Kemudian Ki Sarap mulai membidikkan senapannya ke arah sasaran, tapi secara tiba-tiba dengan gerakan yang cepat Ki Sarap membalikkan tubuhnya ke arah barat, bidikan senapannya ditujukan ke tempat kosong, dengan hati-hati dia menarik pelatuknya kemudian terdengarlah letusan senapannya.

Ternyata peluru yang ditembakkan tepat mengenai gegombel kerudung sang permaisuri dan terdengar pluk suara gegombel yang jatuh ke tanah tetapi permaisuri sultan tetap di tempatnya semula tak tersentuh oleh peluru yang ditembakkan oleh $\mathrm{Ki}$ Sarap. Jatuhnya gegombel kerudung permaisuri diiringi oleh suara sorak sorai masyarakat yang menyaksikannya. Kesultanan Banten kini telah diperkuat oleh seorang senopati sakti yang berasal dari daerah Gudang Batu yaitu Ki Sarap.

Selanjutnya Ki Sarap diberi gelar kehormatan yaitu "Senopati Nurbaya" kemudian dikenal dengan sebutan $\mathrm{Ki}$ Nurbaya. Ia menjalankan tugas utamanya mengamankan wilayah Laut Jawa terutama teluk Banten dan Pelabuhan Karangantu. Ki Nurbaya kemudian memindahkan pusat pertahanannya ke daerah Pulo Kali. Karena tugasnya selalu menjaga laut maka ia pun diberi gelar dan lebih terkenal dengan nama Ki Jagabaya atau Ki Jaga Laut. Alasan pemindahan pusat pertahanan ini, karena Pulo Kali dianggap sebagai tempat yang sangat strategis sehingga dapat memudahkan Ki Nurbaya untuk memantau daerah kekuasaannya.

Ia memusatkan pertahanannya di Pulo Kali (berasal dari kata pulo kalih yang berarti Pulau Dua). Tempat ini sekarang menjadi sebuah kampung yang berada di wilayah Kecamatan Pulo Ampel dan terkenal dengan kegiatan Pasar Rakyat pada hari Selasa dan Jumat. Apabila mengintai musuh, ia melakukannya dari puncak Gunung Santri sebab dari tempat ini mudah baginya untuk melihat ke arah laut lepas, melihat kapal yang datang dan pergi dari Bojonegara dan berkomunikasi dengan Pulo Kalih dan menara Banten. Ki Jagabaya atau Ki Jaga Laut menggunakan isyarat-isyarat bahaya dengan cara sebagai berikut: apabila bahaya terjadi di siang hari mereka menggunakan sinar matahari yang dipantulkan melalui cermin. Apabila bahaya terjadi malam hari mereka menggunakan isyarat kobaran api unggun. Semua itu dilakukan dari puncak Gunung Santri dan dapat dipantau dari Pulo Kalih dan Menara Banten.

Saat usianya menjelang senja, Ki Patih Nurbaya menyadari tentang pentingnya kaderisasi atau generasi penerus. Ia pun menurunkan ilmunya terutama ketangkasan khusus yaitu ilmu bela diri "Pencak Silat Banten" yang disebutnya bandrong. Ilmu itu secara khusus diturunkan kepada putra Sultan Maulana Hasanudin, selanjutnya pada para punggawa dan prajurit serta muridmuridnya yang berada di Pulo Kali dan Gudang Batu Waringin Kurung.

Pendidikan ketangkasan dan kedigjayaan itu dipusatkan di Pulo Kali dan dibina langsung oleh kedua kakak beradik Ki Sarap dan Ki Ragil. Di sanalah mereka berdua menghabiskan masa tuanya. Setelah meninggal, mereka berdua dimakamkan di pemakaman umum di daerah Kahal wilayah Kecamatan Pulo Ampel. Hingga sekarang tempat itu dikenal dengan sebutan "Makam Ki Kahal". Banyak masyarakat yang datang berziarah terutama para pesilat bandrong (http://silatindonesia.com/2008/07/sejarahsingkat-silat-bandrong/ diakses/13agustus2012).

\section{Asal-usul Nama Silat Bandrong}

Mengenai asal-usul nama bandrong diambil dari nama sejenis ikan terbang yang sangat gesit dan dapat melompat tinggi dan jauh, menyerang kerang dengan 
moncongnya yang sangat panjang dan bergerigi sangat tajam. Ikan ini sangat berbahaya karena sekali menyerang dapat membinasakan musuhnya. Ki Patih Jaga Laut atau patih sangat menyukai dan sering memperhatikan gerak-gerik dari ikan bandrong, karena ikan tersebut mempunyai gerakan yang tangkas dan gesit juga memiliki jangkauan lompatan dengan jarak jauh. Akhirnya ia menggunakan nama ikan itu untuk nama ilmu ketangkasan bela diri yang dimilikinya yaitu pencak silat bandrong karena tangkas dan gesit serta berbahaya seperti ikan bandrong.

Setiap aliran pencak silat mempunyai ciri masing-masing pada setiap gerakannya. Semua gerakan keseharian yang dilakukan oleh para pesilat bandrong merupakan gerakan bandrong. Tetapi gerakan yang menjadi ciri khas bandrong pada umumnya adalah:

a. Gerakan tangan dan kaki cenderung cepat, dan gerakannya luas.

b. Menggunakan teknik bawah dengan cepat untuk menjatuhkan lawan dengan cara mengambil kaki lawan dan mengangkatnya ke atas dengan posisi kepala lawan di bawah kemudian dilemparkannya dengan jarak yang sangat jauh (Wiryono, 2005: 30).

\section{Jurus dasar pada silat bandrong:}

$\begin{array}{ll}\text { 1. } & \text { Jurus Pilis } \\ 2 . & \text { Jurus Catrok } \\ \text { 3. } & \text { Jurus Totog } \\ \text { 4. } & \text { Jurus Seliwa } \\ \text { 5. } & \text { Jurus Gebrag } \\ \text { 6. } & \text { Jurus Kurung }\end{array}$

Gerakan dasar langkah silat bandrong:

1. Geleng / giling

2. Cawuk

3. Wiyak

4. Rawus

5. Rambet

6. Pentil

$7 . \quad$ Keprak

8. Sendok

$\begin{array}{ll}\text { 9. } & \text { Jingjing } \\ \text { 10. } & \text { Colok } \\ \text { 11. } & \text { Badug } \\ \text { 12. } & \text { Tejeh } \\ \text { 13. } & \text { Pukul } \\ \text { 14. } & \text { Depok } \\ \text { 15. } & \text { Goco } \\ \text { 16. } & \text { Sentak } \\ \text { 17. } & \text { Sabet } \\ \text { 18. } & \text { Sepak } \\ \text { 19. } & \text { Dupak } \\ \text { 20. } & \text { Dedeg } \\ \text { 21. } & \text { Bulang baling } \\ 22 . & \text { Gendong } \\ 23 . & \text { Gedog } \\ 24 . & \text { Gunting } \\ 25 . & \text { Sapu } \\ 26 . & \text { Sangsut } \\ 27 . & \text { Gedrig }\end{array}$

http://silatindonesia.com/2008/07/sejara h-singkat-silat-

bandrong/diakses13Agustus2012

\section{Terbentuknya Perguruan Silat Bandrong Renggong Ampel}

Setelah terjadi pertarungan antara Ki Marip salah satu pendekar Bandrong yang berasal dari Pulo Kali dan Bang Imi (Halimi) seorang pendekar dari daerah Kwitang, Betawi, akhirnya setelah kekalahan Bang Imi, keduanya menjalin persahabatan yang erat. Mereka merupakan pendekar dengan kemampuan yang berbeda, yaitu bandrong dari Banten dan silat kwitang dari Betawi yang dipadukan menjadi satu. Dari perpaduan dua guru tersebut lahirlah murid-murid pencak silat bandrong yang bervariasi dalam beberapa versi. Perpaduan ini yang kemudian memunculkan perbedaan antara daerah satu dengan daerah lainnya. Bahkan antara murid yang satu dengan murid lainnya bisa berbeda karena kedua guru yang mengajarkan bandrong memberikan sedikit berbeda gerakan baik tangan atau badan dengan alasan melihat kondisi tubuh murid. Selanjutnya Ki Marip memusatkan Pulo Kali sebagai pusat latihan pengembangan bela diri bandrong, dan 
Bang Imi memusatkan Sumuranja sebagai tempat pengembangan bandrongnya.

Sejak dahulu ketika para guru silat bandrong mengajarkan ilmu silat kepada para muridnya mereka melakukannya secara sembunyi-sembunyi. Latihan silat biasanya dilakukan di dalam rumah mereka, karena guru bandrong tidak mau ilmunya diketahui oleh orang lain selain muridnya. Demikian pula halnya dengan $\mathrm{Ki}$ Marip yang mengajarkan ilmunya kepada murid-muridnya, di antaranya putranya sendiri, Ki Madyuna. Setelah menguasai semua jurus, Ki Madyuna pun mengajarkan Bandrong pada masyarakat di sekitar Pulo Kali. Salah satu muridnya yang telah dianggap mumpuni adalah $\mathrm{Ki}$ Samsudin. Ki Samsudin pun mengajarkan bandrong kepada murid-muridnya, di antara murid-muridnya adalah Asman, Kesidin, Sunaini, Ahmad Rofe'i, Supardi, dan Ali Rahim. Mereka dianggap layak untuk meneruskan dan berhak mengajar silat bandrong kepada masyarakat yang ingin mempelajarinya. Keenam murid $\mathrm{Ki}$ Samsudin masing-masing telah mempunyai murid. Mereka mengajar bandrong sesuai dengan kondisi masingmasing dan tetap mengajar bandrong seperti tradisi mereka, yaitu di dalam rumah gurunya demi menjaga kerahasiaan jurus-jurus yang mereka miliki. Demikian pula halnya dengan Ali Rahim, dikenal dengan panggilan Aba Ali Rahim (Wawancara dengan Ahmad Faroji Jauhari, 10 April 2012).

Aba Ali Rahim, lahir tanggal 1 Januari 1959 di Kampung Ampel, Desa Pulo Ampel, Kecamatan Pulo Ampel, Kabupaten Serang, Provinsi Banten. Ia mengajarkan silat bandrong kepada masyarakat sekitar Kampung Ampel, baik orang tua, pemuda, bahkan anak-anak usia sekolah dasar (SD). Seperti telah disebutkan di atas, Aba Ali Rahim adalah salah satu murid langsung dari $\mathrm{Ki}$ Samsudin yang merupakan pewaris aliran bandrong dari Ki Marip. Dengan dorongan salah satu muridnya yaitu Ahmad Faroji Jauhari, dibentuklah Padepokan Bandrong
Renggong Ampel. Sebelum pembentukan padepokan atau perguruan, Ahmad Faroji terlebih dahulu meminta saran dan petunjuk kepada guru besarnya yaitu Ali Rahim kemudian kepada beberapa tokoh bandrong, di antaranya Mad Saleh, Sujai, dan Rahmani. Kemudian dilakukan musyawarah untuk mencari format yang ideal dari sebuah paguyuban bela diri bandrong (Wawancara dengan Aba Ali Rahim, 9 April 2012).

Untuk nama padepokan, Aba Ali Rahim mengusulkan 3 calon nama perguruan, di antaranya: Darma Ampel, Renggong Ampel, dan Galu Ampel. Renggong diambil dari nama salah satu guru besar bandrong, sedangkan Galu merupakan singkatan dari Gagak Lumayung, salah satu padepokan yang ada di Banten. Akhirnya setelah dilakukan perhitungan secara ilmu falaq oleh Tufli Jauhari salah satu murid Abah Ali Rahim, kurang lebih tiga kali perhitungan, diputuskan Renggong Ampel untuk nama perguruan. Nama Renggong Ampel diambil dari nama salah satu guru besar bandrong generasi ke-7 dan tempat berdirinya padepokan ini. Ki Renggong adalah salah seorang guru besar bandrong pada masa sebelum Ki Marip (seorang guru besar yang mengembangkan bandrong di tahun 1920-an). Sedangkan Ampel adalah Kampung Ampel tempat berdirinya padepokan ini.

Padepokan Renggong Ampel walaupun telah berlangsung lama, secara formal padepokan ini dibentuk dan berdiri pada tanggal 13 Oktober 2010 (5 Dzul Qo'idah 1431 Hijriah) dengan guru besarnya, Aba Ali Rahim Kasim. Menurut Ahmad Faroji (Wawancara 10 April 2012), yang juga berprofesi sebagai dosen di IAIN Serang, transformasi perguruan silat bandrong dari tradisional ke arah modern itu sangat diperlukan. Karena dengan perubahan zaman ini dibutuhkan manajemen yang baik agar seni dan budaya bandrong tidak punah. Karena itulah dibentuk wadah formal dari kegiatan pengajaran aliran bandrong di Kampung 
Ampel ini yang sudah berjalan lama tapi tidak ter-manage dengan baik sehingga menjadi lebih terorganisasi dan berkembang lebih baik lagi. Menurut Faroji, ibarat pisau yang berkualitas baik, apabila tidak diasah dan dijaga dengan baik hanya akan tinggal cerita saja di kemudian hari. Dalam kepengurusan Padepokan Silat Bandrong Ampel Ahmad Faroji diserahi tanggung jawab sebagai sekertaris umum.

Atas dasar kecintaan dan kesadaran akan pelestarian budaya dan seni bandrong yang sudah semakin ditinggalkan oleh generasi mudanya, Padepokan Bandrong Renggong Ampel memulai langkah strategis dengan membentuk organisasi formal yang sudah didaftarkan ke Dewan Pimpinan Pusat Perguruan Pencak Silat Bandrong selaku wadah aliran silat bandrong. Dibentuknya Perguruan Silat Bandrong Renggong Ampel salah satu alasannya adalah agar tidak putus link nya dengan generasi muda, karena dengan membentuk organisasi formal diharapkan bisa tertata lebih baik kegiatan dan juga pengelolaannya (Wawancara dengan Ahmad Faroji Jauhari, 10 April 2012).

Seperti telah diungkapkan sebelumnya bahwa pada zaman dulu aliran bandrong ini diajarkan di dalam rumah, bisa di ruang tengah, bisa juga di dapur. Di samping untuk menjaga kerahasiaan jurus juga ada kesan malu dianggap pamer apabila latihan dilihat banyak orang. Tapi sekarang stigma itu bisa dihilangkan karena justru dengan memperlihatkan keberadaan para pesilat bandrong akan baik untuk regenerasi dan menarik para generasi muda mempelajari aliran bandrong. Padepokan ini dalam struktur organisasinya terdapat 4 bidang yaitu pelatihan dan pengkaderan, kesenian kendang, hubungan masyarakat, dan pengembangan seni dan atraksi. Semua kepengurusan harian dan kepala bidang merupakan murid dari aliran bandrong. Karena ingin agar kepengurusan dan ajaran bandrong selaras sejalan, orang-orang yang duduk dalam kepengurusan organisasi harus mengerti dan menjiwai aliran Bandrong. Jadi mereka selaku pengurus juga merupakan murid dari Aba Ali Rahim (Wawancara dengan Ahmad Faroji Jauhari, 10 April 2012).

Latihan di Padepokan Renggong Ampel dilakukan malam hari, yaitu setiap Selasa malam dan Sabtu malam. Dimulai dari sekitar pukul 08.00 sampai pukul 10.00 malam. Ada sekitar 70 murid yang tercatat dalam daftar padepokan baik yang aktif maupun nonaktif. Regenerasi dan pengembangan padepokan ini sudah berjalan baik. Terbukti sebagian besar murid yang mengikuti latihan adalah usia sekolah, dari tingkat SD sampai dengan SMA. Para murid pun sudah memakai seragam pencak silat warna hitam dengan garis merah dan sabuk merah. Seragam ini menjadi hal yang baru di padepokan bandrong. Karena sebelumnya mereka tidak mempunyai seragam khusus padepokan. Ini disebabkan karena dalam sejarah pengembangan aliran bandrong ini bersifat tertutup dan pilihan. Seorang guru hanya mengajarkan pada orang-orang tertentu saja yang dianggap mampu dan layak untuk diajarkan ilmu bandrong. Oleh karena sifatnya yang tertutup tidak banyak orang yang mempelajari dan menguasai aliran bandrong ini. Tapi dengan diterapkan inklusivitas, aliran bandrong dapat lebih berkembang dan dipelajari banyak orang.

Pada zaman dahulu tidak mudah bagi seorang guru menerima seseorang untuk dijadikan sebagai murid. Karena seorang guru benar-benar selektif dalam memilih murid untuk dapat menerima seluruh ilmu yang akan diturunkan kepadanya. Bagi seorang murid, selain harus mempunyai niat yang mantap juga mampu menjalankan amanat yang diberikan guru kepadanya. Sekarang persyaratan untuk menjadi murid aliran bandrong tidak seketat dulu. Akan tetapi, beberapa hal dasar harus tetap dijalankan sang murid. Seperti menjaga dirinya agar tidak secara sembarangan menggunakan keahlian bandrongnya. Karena selain 
wajib menjaga amar ma'ruf nahi munkar juga akibat buruk pada lawan yang ditimbulkan dari keampuhan jurus bandrong (Wawancara dengan Aba Ali Rahim, 9 April 2012).

Jurus bandrong di Padepokan Renggong Ampel terdiri dari 6 jurus pokok. Masing-masing jurus pokok ini mempunyai 4 jenis gerakan. Gerakan masing-masing jurus ini terdiri dari gerakan polos, gerakan totog, gerakan seliwe, dan gerakan kombinasi. Jurus-jurus pada aliran bandrong mempunyai ciri khas gerak, yaitu gerakan tangan dan kaki sangat cepat. Posisi tangan yang terbuka dan teknik bawah yang cepat dapat digunakan untuk menjatuhkan lawan dengan cara mengambil kaki lawan dan mengangkatnya ke atas dengan posisi kepala lawan di bawah kemudian dapat dilemparkan dengan jarak yang sangat jauh. Jurus bandrong ini adalah jurus yang dikatakan bertahan sekaligus menyerang. Selain melindungi pertahanan juga gerakannya sebagai serangan kepada lawan. Makanya posisi tangan terlihat terbuka dapat memancing lawan untuk melakukan serangan. Dalam istilah $\mathrm{KH}$ Mansyur, hanya ada dua pilihan yang ditawarkan kepada lawan ketika berhadapan dengan pesilat bandrong, ingin jatuh terlentang atau jatuh telungkup. Selain gerakan cepat dalam menjatuhkan lawan, jurus bandrong yang membahayakan lawan adalah pukulan datar yang mengarah rusuk dan ulu hati. Terbukti dalam pertandingan pencak silat yang diikuti oleh wakil perguruan bandrong pada tahun 1984, lawan bertandingnya sampai ada yang meninggal dunia. Salah satu alasan inilah yang membuat wakil dari aliran bandrong tidak mengikuti lagi berbagai pertandingan pencak silat yang diselenggarakan oleh IPSI (Ikatan Pencak Silat Indonesia) di semua ajang pertandingan.

\section{Struktur Organisasi}

Organisasi adalah kesatuan sosial yang dikoordinasikan secara sadar, dengan sebuah batasan yang relatif dapat diidentifikasi, yang bekerja secara terus menerus untuk mencapai suatu atau sekelompok tujuan yang telah ditetapkan (Dahlan, 2011: 271). Padepokan Renggong Ampel juga memiliki struktur organisasi. Kegunaan organisasi ini adalah menjadi pemersatu secara sosial sekaligus juga menjadi ikatan emosional dalam perguruan yang biasa disebut saudara seperguruan. Dalam persatuan tersebut dibuat aturan yang mengikat dengan berbagai ketentuan dan hukum apabila ada pelanggaran yang menjadi tempat untuk mencapai tujuan. Tujuan utama dari terbentuknya Organisasi Perguruan Silat Bandrong Renggong Ampel adalah melestarikan pencak silat bandrong sebagai budaya asli bangsa Indonesia.

Dalam struktur Organisasi Perguruan Silat Bandrong Renggong Ampel terdapat 4 bidang yaitu pelatihan dan pengkaderan, kesenian kendang, hubungan masyarakat, dan pengembangan seni dan atraksi. Semua pengurus harian dan kepala bidang merupakan murid dari aliran bandrong, karena ingin agar kepengurusan dan ajaran bandrong selaras sejalan. Orang-orang yang duduk dalam kepengurusan organisasi harus mengerti dan menjiwai aliran bandrong. Jadi mereka selaku pengurus juga merupakan murid dari Aba Ali Rahim.

Adapun formatur pembentukan susunan kepengurusan Padepokan/ Perguruan Bandrong Renggong Ampel Periode 2010-2015 adalah:

I. Dewan Pembina:

1. Kepala Desa Pulo Ampel

2. Ketua RW 02 Kampung Ampel, Desa Pulo Ampel

3. Serda Hamdani (Kodim 0601 Pandeglang)

II.Dewan Penasihat :

1. H. Kasim

2. H. Komaruddin Hasan

3. H Saniin, S,Ag 
4. Rahmani

5. Asmuni Kasim, S.Pd

6. H. Rusdi, S.Pdl

7. H. Hilman Ali, S.Ag

8. Suwirto Nuri

III. Dewan Kehormatan :

1. Abah Kasidin

2. Abah Asman

3. Abah Rofe'i

4. Abah Supardi

IV. Guru Besar/ Pelatih :

Abah Ali Rahim Kasim

V. Pengurus Harian :

Ketua : Mad Saleh Kesidin, S.Pd

Wakil Ketua: Ahmad Sujai Muhaeriji, S.Pd

Sekretaris : Ahmad Faroji Jauhari, S. Ag, M.Pd

Wakil Sekretaris : Sadeli Kasim

Bendahara : Manudin Sanid

Wakil Bendahara: Tufli Jauhari, S.Pd

Bidang-bidang:

A..Pelatihan dan Pengkaderan :

1. Rusminto

2. M. Yusuf

3. Dimyati

B. Kesenian Kendang

1. Samhari

2. Mahmud

3. Madsai

4. Suhendi

5. Ahmad Sufianto

6. Alifuddin

7. Khairul Efendi

8. Rosyid

9. Ali Murdfani

10. Hartono

C. Hubungan Masyarakat :

1. Odi Purnama

2. Nuryanto

3. Fajar Andriani

D. Pengembangan Seni Atraksi :

1. Edi Husnedi

2. Sulhi
3. Mishak

4. Nawian

\section{Perkembangan Pencak Silat Bandrong dari Masa ke Masa}

Sekitar tahun 1920-1940 Masehi, ketika silat bandrong berada di bawah kepemimpinan guru besar $\mathrm{Ki}$ Marip, seorang pendekar bandrong berasal dari Pulo Kali (1880-1940 M), datang seorang tokoh persilatan Betawi dari Cempaka Putih Jakarta ke pesisir Pulo Kali Bojonegara, yang bernama Hilmi, terkenal dengan sebutan Bang Imi. Tujuan kedatangannya ke Banten adalah untuk menambah wawasan dan pengetahuan di bidang persilatan Banten. Bang Imi adalah pesilat yang menguasai silat kwitang Betawi. Dalam perkenalannya, Ki Marip dan Bang Imi bertukar jurus dalam sebuah pertarungan silat. Hanya dalam beberapa langkah Bang Imi dapat dijatuhkan oleh Ki Marip. Dari peristiwa inilah akhirnya Ki Marip dan Bang Imi menjalin persahabatan. Buah dari persahabatan tersebut ternyata dapat mempengaruhi aliran bandrong dengan variasi dan pendalaman jurusnya karena ada unsur silat kwitang Betawi yang menambah wacana seni yang berbeda. Masuknya unsur-unsur dari aliran silat lain seperti Cimande, Beksi, Kung Fu, Merpati Putih, dan lain-lainnya juga menambah kekayaan jurus dan gerak dari aliran bandrong.

Dari perpaduan dua guru Ki Marip dan Bang Imi dan dari dua jenis jurus, yaitu bandrong Banten dan jurus kwitang Betawi, maka lahir murid-murid pencak silat bandrong yang bervariasi dalam beberapa versi:

1. Sebagian murid ada yang tetap mempertahankan kemurnian jurus-jurus bandrong asli, mereka tidak mau menerima jurus dari aliran lainnya kecuali hanya untuk pengetahuan dan wawasan.

2. Sebagian murid bandrong ada yang lebih cenderung kepada jurus-jurus 
kwitang dari Bang Imi, karena mereka lebih tertarik pada hal-hal baru.

3. Sebagian lagi murid bandrong lebih cenderung kepada jurus-jurus bawaan Ki Marip sendiri, yang sudah dipengaruhi oleh jurus-jurus hasil pengembaraannya di dunia persilatan dari Timur.

4. Murid-murid bandrong lainnya ada yang menggabungkan dua aliran dari $\mathrm{Ki}$ Marip dan Bang Imi menjadi penggabungan yang seimbang dan serasi.

Dari kedua guru besar itu perguruan silat bandrong berkembang di seputar Bojonegara, Cilegon, dan Lampung. Terdapat sekitar 30 padepokan silat bandrong yang tersebar di ketiga daerah tersebut. Masing-masing padepokan mempunyai nama yang berbeda satu dengan yang lain. Tapi tetap mereka berasal dari aliran yang sama yaitu silat bandrong. Selain Bandrong Renggong Ampel ada beberapa nama lain, di antaranya yaitu Bandrong Sapu Jagat, Bandrong Banteng Malang, Bandrong Jalak Emas, dan lain lain. Semua perguruan memakai nama bandrong di depan nama padepokannya karena mereka berasal dari aliran yang sama. Hanya penambahan gerak dan variasi dari unsur silat Betawi dan aliran silat lain membedakan satu padepokan dengan padepokan yang lain.

Murid dan anggota silat bandrong tersebar di berbagai daerah, tapi tidak terorganisasi dengan baik. Hal ini menimbulkan keprihatinan dari para sesepuh dan keluarga besar bandrong. Atraksi dan seni bandrong dikenal luas sampai manca negara tapi tetap bagaikan organisasi tanpa bentuk, terkenal dan populer tapi tidak jelas siapa yang bertanggung jawab. Menyadari akan hal ini dan didorong oleh semangat untuk mengangkat jati diri dan kiprah Perguruan Pencak Silat Bandrong, beberapa tokoh persilatan bandrong pada tahun 2001 mengadakan musyawarah secara maraton yang menghasilkan suatu kesepakatan dan kebulatan tekad "Perguruan Pencak Silat Bandrong harus bangkit kembali". Hal ini pula yang telah menginspirasi pengurus perguruan silat bandrong Renggong Ampel untuk menata keanggotaan perguruan agar lebih baik (http://www.faisalbantani.com/2011/03/per guruan-silat-bandrong-banten.html/diakses 3 agustus 2022).

Saat ini keanggotaan silat bandrong Renggong Ampel tidak terbatas pada murid laki-laki saja tetapi mulai banyak diminati oleh murid-murid perempuan yang terdiri dari usia SD hingga perguruan tinggi. Pengurus Perguruan Pencak Silat Bandrong Renggong Ampel terus berupaya untuk memberdayakan kader-kadernya secara modern dan profesional agar dapat terus mentransformasikan diri dalam dinamika perkembangan zaman dan senantiasa memegang teguh amanat leluhur tanpa harus kehilangan jati diri sebagai pendekar bandrong. Tapi dengan semangat modernisasi dan kesungguhan, diharapkan Perguruan Pencak Silat Bandrong Renggong Ampel Banten dapat menjadi wadah yang positif bagi anggotanya (Wawancara dengan Ahmad Faroji J, 10 April 2012) .

\section{PENUTUP}

Kesadaran akan perlunya manajemen yang baik diaplikasikan oleh para murid dan kasepuhan bandrong di Desa Ampel dengan membentuk kepengurusan formal dengan nama Padepokan Bandrong Renggong Ampel. Dengan adanya wadah formal dapat mengembangkan aliran bandrong ini ke arah yang lebih baik. Pengelolaan yang terarah dan terorganisasi dapat membuka peluang kepada generasi muda untuk mengetahui, mempelajari, dan mencintai budaya asli daerahnya sendiri. Diharapkan untuk padepokan bandrong lain dapat juga mengikuti langkah yang telah dijalankan oleh Padepokan Renggong Ampel dan 
berlomba menjadi yang terbaik dalam pengelolaan dan regenerasinya.

Besar harapan dari pecinta seni dan budaya silat asli Banten untuk melihat persaingan secara positif dari Padepokan Bandrong Renggong Ampel khususnya dan perguruan silat lain pada umumnya dalam memajukan aliran silatnya dengan manajemen modern. Akan sangat membanggakan apabila suatu waktu nanti menyaksikan kepiawaian para pendekar pencak silat dari bandrong dalam memamerkan kehebatannya di kejuaraan dunia pencak silat. Atau kejuaraan antarpadepokan bandrong yang diikuti oleh berbagai negara dengan nama padepokan yang beraneka ragam.

\section{DAFTAR SUMBER}

\section{Buku}

Dahlan, Halwi M. 2011.

"Pencak Silat Panglipur Tinjauan Sejarah Budaya", dalam Patanjala Vol. 3, No.2, Juni 2011, hal 260. Bandung: BPSNT Bandung.

Damayanti, S. 2000.

Perbandingan Ibing Pencak Silat Gaya Cimande dan Gaya Cikalong dan Sanggar Pager Kencana dan Sanggar Panglipur Bandung. Skripsi. Bandung: FPBS UPI.

Dinas Pendidikan. 2003.

Profil Seni Budaya Banten. Bandung: Disdik Provinsi Banten.

Disbudparpora Kabupaten Banten. 2009.

Khasanah Seni Tradisional
Kabupaten Serang. Banten:
Disporabudpar Kab. Serang.

DPP Perguruan Pencak Silat Bandrong. 2001.

Pencak Silat Bandrong Ngagurat Tapak Leluhur Banten. Jakarta: P.T. (Persero) Pelabuhan Indonesia II.
Michrob, Halwany dan A. Mudjahid H. 1993.

Catatan Masa Lalu Banten. Serang: Saudara.

Muzayyanah, Siti. 2004.

Pencak Silat Aliran Bandrong pada

Padepokan Silat Bandrong Pulo

Kali di Desa Ampel. Skripsi UPI.

Setiawan, Irvan. 2011.

"Eksistensi Seni Pencak Silat di

Kabupaten Purwakarta (Kajian tentang Strategi Adaptasi)", dalam Patanjala Vol. 3, No. 3, September 2011. Bandung: BPSNT Bandung.

Seksi Kebudayaan. 1990.

Kesenian Tradisional Kabupaten Serang. Serang: Depdikbud.

Tim Penyusun Subdin Kebudayaan. 2003.

Profil Seni Budaya Banten. Serang:

Disdik Provinsi Banten.

Wiryono, Herry, et al. 2005

Padepokan Pencak Silat Bandrong di Propinsi Banten. Bandung: BKSNT Bandung.

\section{Internet}

http://www.faisalbantani.com/2011/03/per guruan-pencak-silat-bandrongbanten.html/ (diakses13 Agustus 2011)

http://www.tabloiddbuz.com/2011/01/perg uruan-pencak-silat-bandrong.html (diakses13Agustus 2012)

http://silatindonesia.com/2008/07/sejarahsingkat-silat-bandrong/ (diakses13Agustus 2012

\section{Wawancara}

Nama : Aba Ali Rahim Kasim

Usia : 53 tahun

Alamat : Kampung Ampel, Desa Pulo Ampel, Kecamatan Pulo Ampel 
Tanggal : 9 April 2012

Nama : Ahmad Faroji Jauhari, S.Ag,

Usia $\quad$ : 37 Tahun

Alamat : Kpg. Legok dalam, Kel.

Drangong, Kec. Taktakan

Kota Serang.

Tanggal : 10 April 2012 